Article

\title{
Investigating the Determinants of Greek Households Food Waste Prevention Behaviour
}

\author{
Theodora Kritikou ${ }^{1, *}$, Dimosthenis Panagiotakos ${ }^{2} \mathbb{D}$, Konstantinos Abeliotis ${ }^{3}\left(\mathbb{D}\right.$ and Katia Lasaridi ${ }^{1, *}$ (D) \\ 1 Department of Geography, School of Environment, Geography and Applied Economics, \\ Harokopio University of Athens, 70 El. Venizelou, 17671 Athens, Greece \\ 2 Department of Nutrition and Dietetics, School of Health Science and Education, Harokopio University of \\ Athens, 70 El. Venizelou, 17671 Athens, Greece; dbpanag@hua.gr \\ 3 Department of Economics and Sustainable Development, School of Environment, Geography and Applied \\ Economics, Harokopio University of Athens, 70 El. Venizelou, 17671 Athens, Greece; kabeli@hua.gr \\ * Correspondence: kritikou@hua.gr (T.K.); klasaridi@hua.gr (K.L.)
}

check for updates

Citation: Kritikou, T.; Panagiotakos, D.; Abeliotis, K.; Lasaridi, K. Investigating the Determinants of Greek Households Food Waste Prevention Behaviour. Sustainability 2021, 13, 11451. https://doi.org/ $10.3390 /$ su132011451

Academic Editors: Piergiuseppe

Morone, Antonis A. Zorpas,

Mejdi Jeguirim and Maria K. Doula

Received: 6 April 2021

Accepted: 12 October 2021

Published: 16 October 2021

Publisher's Note: MDPI stays neutral with regard to jurisdictional claims in published maps and institutional affiliations.

Copyright: (c) 2021 by the authors. Licensee MDPI, Basel, Switzerland. This article is an open access article distributed under the terms and conditions of the Creative Commons Attribution (CC BY) license (https:// creativecommons.org/licenses/by/ $4.0 /)$.

\begin{abstract}
Food waste prevention is globally an urgent policy priority. Multiple studies have demonstrated that in the developed world, households are the main producers of food waste along the food supply chain, being responsible for about half of the edible food wasted. This study aims to analyse consumers' food waste behaviour and identify the factors that influence food waste generation in Greek households. A survey of 921 Greek households was conducted using a structured questionnaire based on the explanatory framework of the Theory of Planned Behaviour, which is currently the most widely used cognitive model in environmental psychology. The study investigated the validity of relations between the main model parameters (attitude towards food waste, subjective norms, perceived behavioural control, intention, and self-reported behaviour), in addition to knowledge regarding food waste prevention, general environmental knowledge, planning and shopping habits and demographic characteristics. Results demonstrated that food waste prevention Intention and food provisioning habits are direct determinants of food waste generation Behaviour. Intention was predominantly determined by General Environmental Attitude, followed by Perceived Behavioural Control, Attitude towards Food Waste, and Consequences/Outcomes of waste prevention, while Subjective Norms did not exert a statistically significant influence, indicating that formal and informal environmental education can positively influence food waste prevention behaviour through a combination of experiential actions and instruction. The findings of the study can inform policymaking and support the development of effective campaigns for food waste prevention at the consumption stage.
\end{abstract}

Keywords: food waste prevention; theory of planned behaviour; sustainable education; structural equation modelling

\section{Introduction}

Food loss and waste (FLW) constitute a crucial sustainability challenge. It is estimated that $1 / 3$ of all food produced, or approximately 1.3 billion tons per year, is lost or wasted globally [1], while at the same time one in every nine people faces hunger. The environmental impacts, in terms of the embedded natural resources lost and greenhouse gases emitted from the production of discarded food, are significant and undermine the planet's sustainability. The related concerns are reflected in the United Nations Sustainable Development Goals (SDG) target 12.3, which requires halving per capita global food waste at the retail and consumer levels and reducing food losses along production and supply chains, including post-harvest losses by 2030 [1-3].

Food Loss (FL) is defined as the decrease in edible food mass that occurs at production, post-harvest, and processing level in the FSC, while Food Waste (FW) means the food that could have been consumed by people, but this did not happen, due to wrong behaviours at the end stages of the Food Supply Chain (FCS) [2-4]. The term FLW includes loss and 
waste in the different stages of FSC, from the farm to the fork, i.e., primary production, processing and manufacturing, retail and other distribution on food, restaurants and food services and households [1-3]. In medium and high-income countries, over half of the FLW occur in the distribution and consumption stage. In less developed countries, food is lost mostly during the production and post-harvest, mainly due to losses at the handling and storage phase [5].

In the EU alone, it is estimated that $129 \mathrm{Mt}$ of food waste was generated in 2019, amounting to about $20 \%$ of the food produced. Vegetables, fruit, and cereals are the food groups that make the most considerable amount of food waste. The consumption stage has, by large, the largest share $(46 \%)$, almost twice the amounts generated during the primary production $(25 \%)$ and processing and manufacturing stages (24\%). Distribution and retail account for a very small fraction of the food waste generated in the food supply chain in the EU [6]. Thus, FW prevention at the consumption stage is of high priority. Moreover, it constitutes one of the most effective means to reduce the related environmental impacts, since the effect of this stage adds up the different burdens along the FSC [7-9].

As policy priorities move up the waste hierarchy, from safe disposal to recycling and further to prevention, the behaviour of households has become as important a factor as the technical and economic aspects of waste management. It has gained attention in both academic research and decision-making. Understanding the context of FW generation is essential for developing effective evidence-based behaviour change interventions and policies [10]. Behaviour change encompasses a full range of interventions that drive and sustain new attitudes, behaviours and practices when combined. Unsustainable behaviour may be deeply entrenched in people and powerful catalysts are required to change habits towards more sustainable behaviours, such as FW prevention. People need help to make sustainable choices. This can be achieved by providing them with education, skills, and high-quality information. Understanding the mechanisms and causes of food waste behaviour is essential for designing policies, interventions, programmes, and campaigns to enhance such skills and effectively promote food waste prevention [11-16].

In Greece, there is a scarcity of studies investigating FW generation, prevention, and related behaviours at the household or individual level $[2,11-14,17,18]$ leaving a gap in the understanding required to develop efficient food waste prevention actions.

The study aimed to investigate the factors influencing FW behaviour of Greek households, through the development of a conceptual framework based on the Theory of Planned Behaviour (TPB), expanded with specific factors that have been shown to enhance its explanatory capacity in related studies in other countries. The overarching aspiration is to provide valuable indicators to policymakers for the development of targeted household FW prevention action plans and awareness-raising campaigns, at a time when the country develops its Specific Food Waste Prevention Programme, as foreseen in the revised Waste Framework Directive (EU 2018/851).

\section{Background and Theoretical Framework}

\subsection{Theory of Planned Behaviour-TPB}

In the last decade, there has been particularly intense interest in studying the use of social psychology theories in analysing the public's views and behaviour and the influencing factors towards waste prevention actions, especially regarding FW. Most relevant studies are based on the Theory of Planned Behaviour, which is currently the most widely used cognitive model in environmental psychology [19-28].

The TPB argues that Behaviour (B) is determined by the individual's Intention (BI) to perform, or not perform this behaviour. Intention is in turn influenced by Attitude (ATT) towards the behaviour, that is, the individual's positive or negative appreciation of performing the behaviour, Subjective Norms (SN), namely the perceived social pressure to perform the behaviour and the need to conform with the expectations of significant others (such as family, friends or neighbours), and Perceived Behavioural Control (PBC), 
i.e., the perception which someone has about his ability to apply the behaviour and about the influence of external conditions on his ability to adopt this behaviour (Figure 1) $[27,28]$.

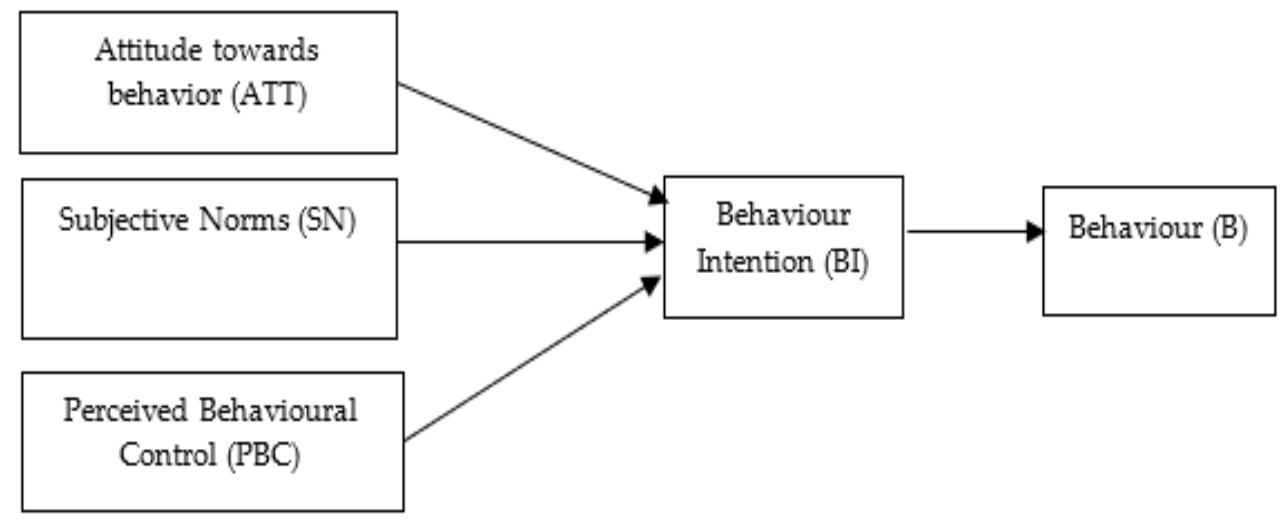

Figure 1. Theory of Planned Behaviour-TPB [27,28].

Generally, the theory supports that the more favourable the ATT and SN, the greater the $\mathrm{PBC}$, the stronger the person's intention to perform the behaviour in question. TPB allows for the incorporation of additional variables, provided that these variables make a significant contribution to the explanation of behaviour [28].

\subsection{Application of TPB on Household FW Prevention}

FW generation from households results from a sum of different behaviours that may influence the likelihood of wastage or the quantities of discarded food. It is a consequence of various attitudes spanning general perceptions and stances about food, nutrition, care about family members and prosperity, to planning food purchases, storage, cooking, serving, and eating habits [29-32].

Some of the most commonly identified behaviours that result in household FW generation include: buying and/or cooking too much, not planning meals in advance, failing to compile or comply with a shopping list, failing to carry out a food inventory before shopping, impulse purchases, and throwing away food that has passed its sell-by/best before date [3], the desire to be a "good" provider for family members, especially children and guests [26,32], and the desire to shop, cook and prepare food with convenience (e.g., fewer trips to the shops means over-purchasing) [33-35].

Moreover, low public awareness of the negative environmental impacts of FW [29-36], in combination with the lack of knowledge about one's FW generation, and the perception that the responsibility for FW lies with the food industry and supermarkets rather than the individual [37-39], influence the quantity of household FW generated. People who are most aware of the effects of their actions are more likely to engage in pro-environmental behaviours and actions. On the contrary, those who believe that their actions are insignificant and that change can only come from the administrative mechanism will become inactive, since they already have laid the responsibilities elsewhere [29-31]. Guilt and health concerns have also been reported as important drivers for FW generation at the household [40,41].

Sociodemographic features of household members such as gender, age, education level, marital status, income, and household size have also been demonstrated to have predictive value concerning FW generation and adoption of FW prevention behaviours [42]. Household size and income are positively correlated with the quantity of FW generated, as has been shown in several studies in different geographic contexts [43-46].

Stefan et al. [25] applied the TPB to investigate household FW generation in Romania and found that ATT was the only classic TPB construct associated with the intention not to waste food. That intention was not significantly associated with a cross-sectional selfreported measure of FW behaviour. On the other hand, in a relevant study in Iran [19], FW generation behaviour was highly influenced by intention, which in turn was influenced 
by ATT and PBC, with the most significant predictor the ATT. A study of household FW prevention behaviours in the UK, focusing on fruit and vegetable waste, found that all the factors (ATT, SN and PBC) of the classic TPB had significant predictive values on intention, in addition to self-identity and anticipated regret, which also made a substantial contribution to the prediction of intention. The authors also identified an intention-behaviour gap in the FW generation, which may be attributed to the behaviour of other members of the household and the strength of habit [20].

In an extensive mail survey in Switzerland on the determinants of the self-reported amount of FW in households, the classic TPB factors were found to be significant, together with the good provider identity [26]. A somewhat different combination of explanatory paths was identified by Mondejar-Jimenez et al. [22] in an exploratory study of Spanish and Italian youths; ATT and PBC were found to be the main components responsible for intention, while intention, $\mathrm{SN}$, and $\mathrm{PBC}$ were the most important determinants of positive (i.e., FW prevention) behaviour. In Denmark [24], food-related routines (i.e., planning, shopping, and leftovers reuse) were demonstrated to be the main drivers of FW generation, in addition to PBC, while in another UK study, based on super-market customers, habits, emotions, SN, PBC, and intentions were all shown to have a role to play in determining self-reported FW behaviour [23].

The results of these studies indicate the validity of an extended TPB model in investigating the main determinants of the self-reported HFW generation behaviour in different countries and/or different population segments, to inform policymakers and formulate effective HFW reduction campaigns.

The following section presents the extended TPB model used in this study to investigate the determinants of Greek households FW prevention behaviour, along with the specific research hypotheses that formulate the selected model are presented.

\subsection{Research Hypotheses}

On the first level, this study sought to explore if the three factors of the classic TPB may predict Intention to prevent FW generation in Greek households. Subsequently, it investigated whether additional constructs, selected based on the relevant literature, may increase the model's predictive power for this Intention. The final aim was to examine the role of the Intention and/or the additional factors reviewed to predict the self-reported FW generation. The conceptual model developed in the study is illustrated in Figure 2. The model was tested using Structural Equation Modelling (SEM) techniques, with the following hypotheses.

$\mathrm{H} 1-\mathrm{H} 4$ are the classic TPB hypotheses: it is expected that attitudes (ATT), subjective norms (SN), and perceived behavioural control (PBC) will account for significant variance in the intention (BI), therefore ATT, $\mathrm{SN}$ and $\mathrm{PBC}$ will emerge as positive predictors of $\mathrm{BI}$. Moreover, it is expected that the intention (BI) will be a significant and negative predictor of food waste generation behaviour (B), as the greater the intention to prevent food waste, the lower the food waste generation behaviour that will be observed.

H5-H8 are additional hypotheses expanding the classic TPB model to increase its behaviour intention (BI) explanatory capacity, following previous research. In this respect, a positive attitude towards various environmental issues (General Environmental Attitude-GEATT), a strong perception of the consequences and outcomes of FW prevention (CONOUT), a good specific knowledge on FW (SK), and a high environmental awareness (EA), will all positively influence the intention to prevent FW (BI) and emerge in the model as positive predictors of BI. Thus:

Hypotheses 1 (H1). FW prevention intention (BI) will be negatively related to FW generation behaviour (B) $[19,22,23]$.

Hypotheses 2 (H2). Attitudes (ATT) to FW will be positively related to intentions to reduce food waste (BI) $[19,20,25,26]$. 
Hypotheses 3 (H3). Subjective norms (SN) will be positively related to intentions to reduce food waste (BI) $[20,23]$.

Hypotheses 4 (H4). Perceived behavioural control for food waste prevention (PBC) will be positively related to intentions to reduce food waste (BI) $[19,22,23,25,26]$.

Hypotheses 5 (H5). The General Environmental Attitude (GEATT) will be positively related to intentions to reduce food waste (BI) [20].

Hypotheses 6 (H6). The perception of the consequences and outcomes of FW prevention (CONOUT), will be positively related to intentions to reduce food waste (BI) [29,36].

Hypotheses 7 (H7). The specific knowledge about the problem of FW (SK) will be positively related to intentions to reduce food waste (BI) [46].

Hypotheses 8 (H8). The environmental awareness (EA) will be positively related to intentions to reduce food waste (BI) [18].

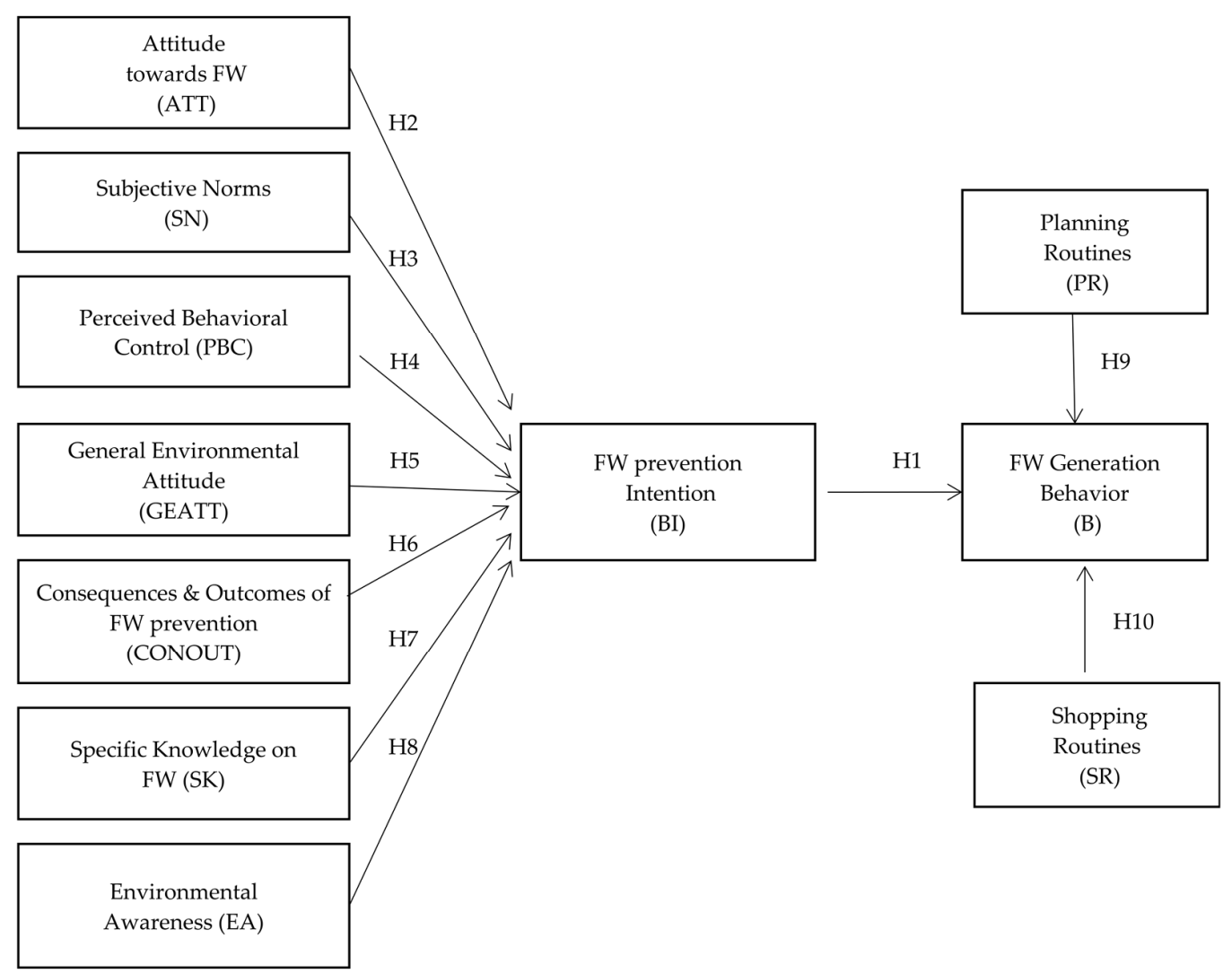

Figure 2. The conceptual model of the determinants of FW behaviour examined.

The last two hypotheses examined in the model concerned the effect of planning and shopping routines directly on FW generation behaviour. Moreover, in many studies [23-26], planning and shopping routines have been shown to highly influence FW generation behaviours directly, irrespectively and without the mediation of the behaviour intention. Planning practices refer to pre-shop habits, such as: use of shopping lists, planning meals in advance, checking inventory levels, etc. Shopping routines refer to shopping activities and habits that occur in the shop, which may lead to excessive food quantities shopping, such as impulse shopping, preference for specific offers and product promotions, etc. Planning routines were measured with three items related to the planning of shopping and meals. Shopping routines were measured with three items referring mainly to the causes of excess purchasing (Appendix A). Thus: 
Hypotheses 9 (H9). Well established planning routines (PR) will be negatively related to $F W$ generation Behaviour (B) [23-26].

Hypotheses 10 (H10). Shopping routines leading to excessive shopping will positively relate to FW generation Behaviour (B) [23-26].

\section{Methodology}

This paper analyses and reports the results on food waste of a broader survey on waste prevention, which contained two distinct sections, one on food waste prevention (reported here) and one on other waste prevention activities (e.g., plastic bags, electrical and electronic equipment, etc.-results not reported here).

\subsection{Sample and Data Collection}

The dataset of the study was collected via a structured questionnaire. The survey addressed Greeks between the age of 18 and 75, who were responsible, at least to some extent, for cooking or food purchases in their household. The participants were asked to fill in the questionnaire after being informed of the purpose of the study and the confidentiality of the data. First, a pilot study with 20 individuals was carried out, to assess the clarity and reliability of the questionnaire. After minor corrections to the initial questionnaire, the complete survey was undertaken from April to June 2017.

A convenience sample of 1000 households (friends, neighbours, and colleagues) was selected. Overall, 921 fully completed questionnaires were collected, providing a response rate of $92 \%$. Most respondents resided in the wider Athens Metropolitan area while a few respondents (2.93\%) lived in other cities.

This method of recruiting is based on the participation of readily available persons, easily accessible and willing to participate in the survey voluntarily, without any financial incentive. This type of sampling cannot be regarded as stratified and representative, as respondents are selected at the convenience of the researchers. However, in this type of study, convenience sampling is not considered a drawback - under the condition that responses present sufficient variability in the examined variables [47-49]. Such sample is commonly used in TPB research [22,47-50], as the aim is to identify relationships among the model variables and not to estimate population parameters.

\subsection{The Questionnaire}

The primary tool of the part of the survey reported herein was a 30 questions part of a more comprehensive structured questionnaire on waste prevention, investigating food waste prevention behaviour based on the extended TPB model presented in Figure 2. The questions (observed variables), and the variables of the model which they measure (latent variables), are provided in Appendix A. All the observed variables were measured on a 5-point Likert scale, unless otherwise stated. Depending on the question, categories on the Likert scale ranged from "strongly disagree (1)" to "strongly agree (5)" and from "never (1)" to "always (5)". The items regarding "SKWP-Specific Knowledge on FW" had a "Yes" or "No" scale, those for "EA-Environmental Awareness" a 3-point Likert scale ("Fully aware of", "Somewhat aware of", and "Not aware").

To increase the validity of the estimate of the self-reported "FW behaviour (B)", the latent variable was measured with four observed variables (items): one on general FW generation, and three on the quantity of waste generated for specific perishable types of food (fruits, vegetables, and leftovers), which are commonly the most wasted fractions. The 5-point Likert scale used was graded as: "Not at all", "A little $(<15 \%)$ ", "Some $(16-30 \%)$ ", "Much $(31-50 \%)$ ", and "Very much $(>50 \%)$ " [46,47]. Participants were asked to mention their estimation about the percentage of every food category and totally they throw away.

Moreover, the questionnaire included a section on demographic data of the respondents (gender, age, education level, marital state, working state, number of household members, and income) and two screening questions for their suitability for the food waste 
behaviour study. To be included respondents should be responsible, at least to some extent, for cooking or food purchases in their household, as the behaviour of these individuals affects the production of food waste $[46,47]$. This condition was ensured by the two screening questions of the last section of the questionnaire ("To what extent are you responsible for food shopping in your household?" and "To what extent are you responsible for cooking and preparing food in your household?"). Those who answered that they did not have any responsibility in either of the questions were excluded from this study.

\subsection{Statistical Analysis-Structural Equation Model (SEM)}

The collected data were analysed using Structural Equation Modelling (SEM) Confirmatory Factor Analysis (CFA) with the statistical analysis software STATA 12 (Texas, USA). SEM, or path analysis, was selected as the appropriate tool to evaluate the FW behaviour model developed in this study (Figure 1). It is a multivariate statistical technique widely applied in behavioural science. SEM allows simultaneously modelling many relationships that use latent variables in the analysis as dependent or explanatory variables. Latent variables cannot be estimated directly (such as attitudes, social pressure, emotion, etc) and their presence is inferred from other variables that can be observed [51]. SEM allows testing relation hypotheses, which is not possible with traditional methods of data analysis. An SEM model consists of a measurement model and a structural model. The first is a set of observed variables representing a small number of latent (unobserved) variables. The measurement model describes the relationship between observed and unobserved variables. The second is a schematic depicting the interrelationships among latent variables [52].

Correlations among the model variables were examined using Kendall's tau-b coefficient. Construct reliability for each latent variable was calculated using Cronbach's alpha coefficient. Values of the coefficient above 0.7 suggest adequate reliability of a construct. This was fulfilled in all cases. The goodness-of-fit of an SEM-CFA model can be detected by a variety of parameters, such as chi-square, $p$-value, comparative fit index (CFI), the goodness of fit index (GFI), adjusted goodness of fit index (AGFI), standardized root mean square residual (SRMR), and root mean square error of approximation (RMSEA). CFI ranges from 0 to 1 and is considered one of the strongest and most reliable indicators since it is not influenced by sample size, estimation method, and regularity of variables. CFI values $>0.9$ are considered as indicative of a good fit, but values $>0.8$ may also be considered satisfactory for complex behavioural models. For RMSEA, values less than 0.05 are good, values between 0.05 and 0.08 are acceptable, values between 0.08 and 0.1 are marginal, and values greater than 0.1 are poor $[49,53]$. In this study, CFI and RMSEA have been used to assess the goodness-of-fit of the tested SEM models.

Researchers specify a priori the interrelationships that are theorised to exist through the specification of a model and then test how well the theoretical model matches the data [54]. If the model is inadequate, SEM can assess the factors that contribute to it, redefining it to fit better with the empirical data. This technique has been used in many studies related to environmental behaviour such as: recycling behaviour [55-57]; consumers environmentally friendly behaviour [50]; attitudes and perceptions on best solid waste management practices [58], etc.

Moreover, an exploratory factor analysis (EFA) was performed, to identify the main factors explaining the variance in Behaviour Intention (BI) and self-reported Behaviour (B). The main results of the EFA, particularly regarding the demographic factors, are also discussed. Statistically significant differences of the different parameters and factors examined on (BI) and (B) were investigated using t-test and one-way ANOVA.

\section{Results and Discussion}

The estimation method used in the SEM-CFA was that of the maximum likelihood. Correlations have been made between the errors of the observed variables as the modification indices suggested. There were 30 observed variables in the initial measurement 
model (14 observed variables measuring the typical variables of TPB and 16 additional variables-Appendix A).

First, the classic TPB model, as illustrated in Figure 1, was tested. Results are presented in Table 1. Based on RMSEA the goodness-of-fit is marginal, while CFI suggests it is satisfactory. The latent variable SN (subjective norms) did not have a statistically significant effect on intention (BI) $(p=0.999)$. Therefore, it was omitted, and a new statistical assessment was performed for a modified TPB model, consisting of the classic TPB model constructs, apart from SN (Table 2).

Table 1. Statistical evaluation of the classic TPB model.

\begin{tabular}{lccccccc}
\hline \multicolumn{2}{c}{ Structural } & Coef. & Std.Err. & $\mathbf{z}$ & $p>\mathbf{z}$ & [95\%Conf.Interval] \\
\hline BI $<-$ & & & & & & \\
& ATT & 0.4210123 & -0.037487 & 11.23 & 0.000 & 0.3475389 & 0.4944857 \\
& SN & 0.2258177 & 163.751 & 0.00 & 0.999 & -320.7196 & 321.1723 \\
& PBC & -0.3551866 & 0.0536904 & -6.62 & 0.000 & -4.604179 & -0.2927755 \\
\hline B $<-$ & & & & & & & \\
& BI & -0.4387278 & 0.0744668 & -5.89 & 0.000 & -0.5846801 & -0.2927755 \\
\hline
\end{tabular}

Goodness-of-fit of the measurement model: RMSEA $=0.1 ; \mathrm{CFI}=0.876$.

Table 2. Statistical evaluation of the classic TPB model, not including SN.

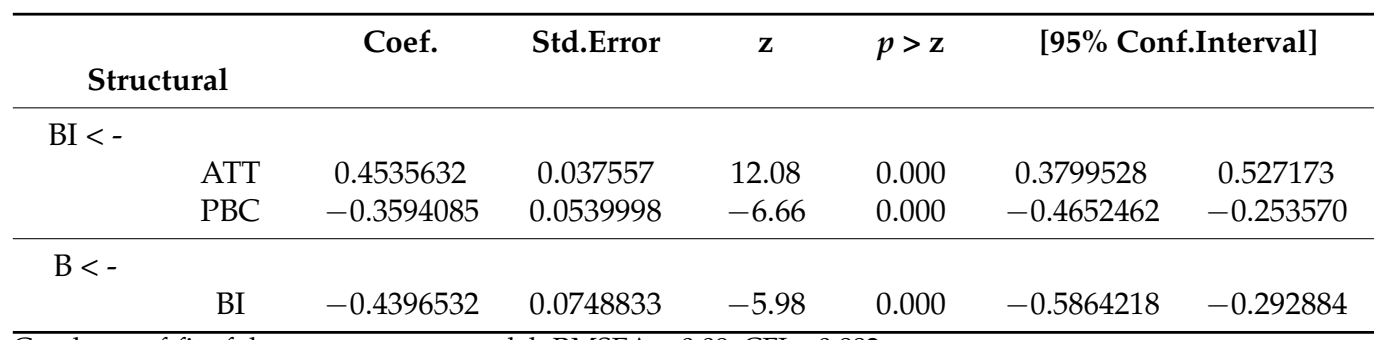

Goodness-of-fit of the measurement model: RMSEA $=0.09 ; \mathrm{CFI}=0.882$.

The goodness-of-fit of the modified TPB model, as indicated by both RMSEA and CFI was improved. The lack of correlation between SN and FW prevention intention (BI) has also been highlighted in several studies [20,25]. FW generation may appear to many as a socially acceptable process, as typically the individuals are not fully aware of the food quantity they waste. Many consumers also believe that food waste is an inevitable consequence of food consumption, so they consider their generation regular, and selfevident practice, which does not indicate an environmentally irresponsible behaviour [59]. In addition, waste prevention behaviours are not publicly visible, therefore prevention may not be sensitive to subjective norms, a finding also common to recycling behaviour studies, especially in cases where the visibility of the behaviour is low, such as in large blocks of flats in urban areas [50].

When the selected additional constructs (GEATT, CONOUT, SK, EA, PR and SRAppendix A) were introduced to the extended TPB model (Figure 2), the goodness-of-fit further improved (RMSEA $=0.08, \mathrm{CFI}=0.876$; Table 3 ). However, not all constructs were statistically significant. "Specific Knowledge on FW (SKWP) and "Environmental Awareness" (EA) did not exhibit a statistically significant correlation with "Behaviour Intention" (BI) ( $p=0.504$ and 0.354 , respectively). The stronger predictive factor for BI was an additional to TPB factor, "General Environmental Attitude" $(\beta=0.52, p<0.001)$, followed by "Attitude towards FW" $(\beta=0.31, p<0.001)$, "Consequences-Outcomes of waste prevention" $(\beta=0.22, p<0.001)$ and "Perceived Behavioural Control" $(\beta=-0.34$, $p<0.001)$. The items for "Perceived Behavioural Control" were negatively stated in the questionnaire (Appendix A), therefore the negative sign of $\beta$ is in accordance with the hypothesis H4 tested and the theory (TPB). 
Table 3. Statistical evaluation of the behaviour model examined (Figure 2).

\begin{tabular}{lccccccc}
\hline \multicolumn{2}{c}{ Structural } & Coef. & Std.Error & $\mathbf{Z}$ & $p>\mathbf{z}$ & \multicolumn{2}{c}{ [95\% Conf.Interval] } \\
\hline BI $<-$ & & & & & & \\
& & & & & & & \\
& ATT & 0.310853 & 0.0360034 & 8.63 & 0.000 & 0.240288 & 0.381419 \\
PBC & -0.341565 & 0.0540329 & -6.32 & 0.000 & -0.447468 & -0.235663 \\
& GEATT & 0.521674 & 0.0840409 & 6.21 & 0.000 & 0.356956 & 0.686391 \\
& CONOUT & 0.217899 & 0.0479821 & 4.54 & 0.000 & 0.123856 & 0.311942 \\
& SKWP & 0.048848 & 0.0730226 & 0.67 & 0.504 & -0.942733 & 0.191970 \\
EA & -0.053200 & 0.0574011 & -0.93 & 0.354 & -0.165701 & 0.059308 \\
\hline B $<-$ & & & & & & \\
& BI & -0.270481 & 0.0829134 & -3.26 & 0.000 & -0.432989 & -0.107975 \\
& PR & 0.193024 & 0.0571598 & 3.38 & 0.001 & 0.080993 & 0.305055 \\
SR & 0.507811 & 0.4463607 & 1.14 & 0.255 & -0.367040 & 1.382662 \\
\hline
\end{tabular}

Goodness-of-fit of the measurement model: RMSEA $=0.08 ; \mathrm{CFI}=0.876$.

In line with the initial hypothesis $\mathrm{H} 1$, behaviour was negatively correlated with intention $(\beta=-0.27, p<0.001)$, which means the greater the FW prevention intention, the lower the FW quantity generated, following theory and several other studies $[19,22,23]$. Somewhat surprisingly though, the behaviour was positively correlated with "Planning Routines" $(\beta=0.19, p<0.005)$, indicating that the better the planning routines, the more FW generated, a finding that deserves further investigation, as it contradicts both reasonable expectations and the results of several studies [23-26]. It is expected that good planning routines, such as checking food stocks before food purchasing, making a shopping list and planning meals in advance, will lead to less food being wasted. Training and mobilising people to adopt such planning routines is a significant component of many campaigns for food waste prevention $[1,3,4,6]$.

It is not clear what might have led to this finding, of a positive correlation between planning routines and FW behaviour. A study artefact cannot be excluded, while the limitations of self-reported behaviour may also have played a role. Alternatively, results may indicate the discrepancies between making plans and holding to them. For example, making a shopping list and keeping to it (which was not included as a question in this study) may not coincide.

Behaviour correlation with "Shopping Routines" was not statistically significant $(p=0.255)$, leading to the rejection of both $\mathrm{H} 9$ and H10. This is also in contrast to other studies [23-26] but may be the outcome of careful shopping routines well established widely to Greek customers, because of their relatively low purchasing power and the deep and long financial crisis experienced in the country. It is worth mentioning that the GDP of Greece has still not reached its pre-2009 levels.

Results in the literature are contrasting. Regarding the main EFA results, there was no significant difference in the behaviour (FW generation) according to gender, educational level, professional status, and income $(p>0.05)$. A recent study in Croatia also did not find a significant correlation of gender with FW behaviour [60]. On the other hand, in a UK study, Barr found that women were more willing to reduce their food waste [61]. In contrast, many studies in other countries indicated that women throw away more food than men $[29,30,44,62]$, possibly because they are the ones responsible for food provisioning and preparation. They often exhibit a "good provider" behaviour, caring for their family members to have sufficient, healthy, fresh food, which is often not consumed, especially when there are children in the household.

In this study, marital status was significantly correlated $(p<0.01)$ with FW behaviour, with married people generating less FW, but the number of household members did not affect the FW generation behaviour $(p>0.05)$. The effect of marital status is not commonly reported in the literature, so it might be worth including it in future studies. On the other hand, many studies have found that the larger the size of the household, the less the per capita food waste produced $[29,30,44,62]$, which was not replicated in this study. 
These differences could possibly be attributed to the economic crisis that prevailed in the previous decade in Greece, which has severely strained household budgets for vast sections of the population. Consumers were still very restrained in spending, leading to reduced food wastage, independent of gender, education level, household size and professional status. However, this hypothesis requires further investigation.

All these findings should always be considered under the light of the main limitation of this type of study: the assessment of the FW generation behaviour through a selfreporting proxy. It is widely accepted that respondents may commonly under-report their FW generation, to provide answers closer to perceived moral norms of avoiding food wastage. This could lead research to false correlations. Nevertheless, it has been shown that the conceptualization of the relationship between attitudes and behaviour, according to TPB being suitable even when behaviour was self-reported, although the level of behaviour variability explained was overestimated when self-reporting measures were used compared to when behaviour measures were objective or observed [21].

\section{Conclusions}

The classic TPB theory was shown to apply to the study of FW prevention behaviour in Greek households, with Attitude and PBC being the two statistically significant predictors of the intention to prevent FW (BI). Moreover, the intention was shown to correlate with the self-reported behaviour, in the expected direction. In contrast, SN, which reflects the individuals' perception of social pressure to reduce FW generation, was not a statistically significant predictor of intention, a common finding with many similar studies. Omitting SN from the model, improved its capacity to explain the variance in FW prevention intention, as indicated by the simplified TPB model goodness-of-fit.

To further improve the predicting capacity, an extended TPB model was examined using four additional variables for intention and two variables directly affecting behaviour, with satisfactory results. SEM was used to determine which other latent variables from General Environmental Attitude, (knowledge about the) Consequences and Outcomes of FW prevention, Specific knowledge on FW, Environmental awareness, Planning routines, and Shopping routines improved the abovementioned simplified classic TPB model. In addition to Attitude and PCB, the General Environmental Attitude and the Consequences and Outcomes of FW prevention had a statistically significant influence on the Intention. Regarding the direct effect on FW generation Behaviour, Planning routines were also found to be statistically significant, while Shopping routines were not.

EFA was also used to shed light on FW generation behaviour by exploring the influence of demographic parameters; however, no statistically significant correlation was identified with gender, educational level, household size, professional status, and income. In contrast, married people were found to generate statistically significantly less FW.

The findings of this study can serve to inform policymakers on how to design and implement effective FW prevention interventions for Greek households, as it indicates that-in addition to the well-established approaches-highlighting the Consequences and outcomes of FW prevention may have a significant impact on enhancing the desired behaviour. Overall, the need to acquire more profound knowledge on the reasons of household FW generation across the different EU member states, and transform it into useful information for decision-makers, in all governance levels, including that of businesses, who are responsible for developing and implementing FW prevention strategies and action plans, is currently more imperative than ever if the EU is to meet its ambitious policy targets, as set in the European Green Deal and the Farm to Fork Strategy $[63,64]$.

Finally, this study adds to the extensive range of studies supporting the TPB's efficacy in studying different environmental behaviours [65].

Author Contributions: Conceptualization, T.K., K.A. and K.L.; methodology, T.K., K.L. and D.P.; data curation, T.K.; formal analysis, T.K., K.L. and D.P.; investigation, T.K.; writing-original draft preparation, T.K.; writing-review and editing, K.L., T.K., D.P. and K.A.; supervision, K.L., K.A. and D.P. All authors have read and agreed to the published version of the manuscript. 
Funding: This study was partially supported.by the postgraduate studies program of the Department of Geography, Harokopio University.

Institutional Review Board Statement: Ethical review and approval were waved for this study as it does not entail sensitive personal information.

Informed Consent Statement: Informed consent was obtained from all subjects involved in the study.

Conflicts of Interest: The authors declare no conflict of interest.

\section{Appendix A}

Table A1. Observed and latent variables of the questionnaire.

\begin{tabular}{|c|c|}
\hline Latent Variables & Observed Variables \\
\hline \multicolumn{2}{|l|}{ Classic TPB model variables } \\
\hline \multirow{2}{*}{$\begin{array}{l}\text { ATT-Attitude towards } \\
\text { FW prevention }\end{array}$} & ATTWP5: It is essential for me not to throw food \\
\hline & $\begin{array}{l}\text { ATTWP6: To buy precisely the quantities of food I need so not to throw them is environmentally } \\
\text { responsible behaviour }\end{array}$ \\
\hline SN-Subjective Norms & SN5: Most people whose opinion I am interested in believe that it is essential not to throw food \\
\hline \multirow{2}{*}{$\begin{array}{l}\text { PBC-Perceived Behavioural } \\
\text { Control }\end{array}$} & PBC5: I believe I can't do anything to reduce the food waste I generate \\
\hline & PBC6: It's difficult to predict precisely how much food my household needs for a regular week \\
\hline \multirow{5}{*}{ BI-Behaviour Intention } & BI5: My intention is not to throw any food at all \\
\hline & BI6: I will check food stocks before making purchases \\
\hline & BI7: I plan to make a list of the food I need to buy \\
\hline & BI8: I estimate that I will plan the meals of the week to make the most of the food I buy \\
\hline & BI9: I want to cook and prepare precisely the amount of food I need for my household \\
\hline \multirow{4}{*}{$\begin{array}{l}\text { B-Behaviour for FW } \\
\text { generation }\end{array}$} & FRUITS: quantities of fruit that are discarded \\
\hline & VEGETABLES: quantities of vegetables discarded \\
\hline & LEFTOVERS: leftovers \\
\hline & TOTAL: the total amount of food not consumed and discarded \\
\hline \multicolumn{2}{|l|}{ Additional variables } \\
\hline \multirow{2}{*}{$\begin{array}{l}\text { GEATT-General } \\
\text { Environmental Attitude }\end{array}$} & GEATT1: We are approaching the limit of the number of people the earth can support. \\
\hline & GEATT2: Every citizen must protect the environment \\
\hline \multirow{2}{*}{$\begin{array}{l}\text { CONOUT-Consequences and } \\
\text { Outcomes of FW prevention }\end{array}$} & $\begin{array}{l}\text { CONOUT3: FW prevention contributes to the conservation of the planet's natural resources } \\
\text { (e.g., water) }\end{array}$ \\
\hline & CONOUT5: By preventing food waste I save money \\
\hline \multirow{3}{*}{$\begin{array}{l}\text { SKWP-Specific Knowledge } \\
\text { on FW }\end{array}$} & SKWP7: $1 / 3$ of the quantity of food produced worldwide is not consumed \\
\hline & SKWP8: In developed countries, most of the food waste is produced by households \\
\hline & $\begin{array}{l}\text { SKWP11: The production of non-consumed food has high environmental costs in energy, natural } \\
\text { resources (soil, water) and greenhouse gas emissions }\end{array}$ \\
\hline \multirow{3}{*}{ EA-Environmental Awareness } & EA2: Climate change \\
\hline & EA3: Greenhouse effect \\
\hline & EA5: Waste management hierarchy \\
\hline \multirow{3}{*}{ PR-Planning Routines } & PR1: Check food stocks before making purchases \\
\hline & PR2: Make a list with the foods you need to buy \\
\hline & PR3: Plan your meals several days in advance \\
\hline \multirow{3}{*}{ SR-Shopping Routines } & SR1: I buy most food in one weekly shopping \\
\hline & SR4: I buy food I did not intend to buy because of offers \\
\hline & SR5: I buy more food than I need to cater for unexpected visitors or emergencies \\
\hline
\end{tabular}

\section{References}

1. Göbel, C.; Langen, N.; Blumenthal, A.; Teitscheid, P.; Ritter, G. Cutting Food Waste through Cooperation along the Food Supply Chain. Sustainability 2015, 7, 1429-1445. [CrossRef]

2. Abeliotis, K.; Lasaridi, K.; Costarelli, V.; Chroni, C. The implications of food waste generation on climate change: The case of Greece. Sustain. Prod. Consum. 2015, 3, 8-14. [CrossRef] 
3. Parfitt, J.; Barthel, M.; Macnaughton, S. Food waste within food supply chains: Quantification and potential for change to 2050. Philos. Trans. R. Soc. B Biol. Sci. 2010, 365, 3065-3081. [CrossRef]

4. Priefer, C.; Jörissen, J.; Bräutigam, K.-R. Food waste prevention in Europe-A cause-driven approach to identify the most relevant leverage points for action. Resour. Conserv. Recycl. 2016, 109, 155-165. [CrossRef]

5. Chaboud, G.; Benoit, D. Food losses and waste: Navigating the inconsistencies. Glob. Food Secur. 2017, 12, 1-7. [CrossRef]

6. Sanchez Lopez, J.; Patinha Caldeira, C.; De Laurentiis, V.; Sala, S. Brief on Food Waste in the European Union; Avraamides, M., Ed.; European Commission: Brussels, Belgium, 2020.

7. Gentil, E.C.; Gallo, D.; Christensen, T.H. Environmental evaluation of municipal waste prevention. Waste Manag. 2011, 31, 2371-2379. [CrossRef]

8. Matsuda, T.; Yano, J.; Hirai, Y.; Sakai, S.-I. Life-cycle greenhouse gas inventory analysisis of household waste management and food waste reduction activities in Kyoto, Japan. Int. J. Life Cycle Assess. 2012, 17, 743-752. [CrossRef]

9. Kummu, M.; de Moel, H.; Porkka, M.; Siebert, S.; Varis, O.; Ward, P. Lost food, wasted resources: Global food supply chain losses and their impacts on freshwater, cropland, and fertiliser use. Sci. Total Environ. 2012, 438, 477-489. [CrossRef] [PubMed]

10. Bortoleto, A.P.; Kurisu, H.K.; Hanaki, K. Model development for household waste prevention behaviour. Waste Manag. 2012, 32, 2195-2207. [CrossRef] [PubMed]

11. Abeliotis, K.; Chroni, C.; Lasaridi, K. Food. In Handbook of Famine, Starvation, and Nutrient Deprivation; Springer: Chambridge, UK, 2017; pp. 327-340. [CrossRef]

12. Abeliotis, K.; Chroni, C.; Lasaridi, K. Consumers' Behavior Regarding Food Waste Prevention. In Encyclopedia of Food Security and Sustainability; Elsevier: Amsterdam, The Netherlands, 2019; pp. 510-514. [CrossRef]

13. Abeliotis, K.; Lasaridi, K.; Chroni, C. Food waste prevention in Athens, Greece: The effect of family characteristics. Waste Manag. Res. 2016, 34, 1210-1216. [CrossRef]

14. Zorpas, A.A. Strategy development in the framework of waste management. Sci. Total Environ. 2020, 716, 137088. [CrossRef]

15. Loizia, P.; Voukkali, I.; Zorpas, A.A.; Pedreño, J.N.; Chatziparaskeva, G.; Inglezakis, V.J.; Vardopoulos, I.; Doula, M. Measuring the level of environmental performance in insular areas, through key performed indicators, in the framework of waste strategy development. Sci. Total Environ. 2021, 753, 141974. [CrossRef] [PubMed]

16. Zorpas, A.A.; Lasaridi, K.; Abeliotis, K.; Voukkali, I.; Loizia, P.; Fitiri, L.; Chroni, C.; Bikaki, N. Waste prevention campaign regarding the Waste Framework Directive. Fresenius Environ. Bull. 2014, 23, 2876-2883.

17. Ponis, S.T.; Papanikolaou, P.-A.; Katimertzoglou, P.; Ntalla, A.C.; Xenos, K.I. Household food waste in Greece: A questionnaire survey. J. Clean. Prod. 2017, 149, 1268-1277. [CrossRef]

18. Abeliotis, K.; Lasaridi, K.; Chroni, C. Attitudes and behavior of Greek households regarding food waste prevention. Waste Manag. Res. 2014, 32, 237-240. [CrossRef] [PubMed]

19. Alibaygi, A.; Ghadimi, S.A.; Azami, A. An analysis of household waste prevention behaviors (case study: Fereidan Town-ship). J. Biodivers. Environ. Sci. 2014, 4, 173-186.

20. Graham-Rowe, E.; Jessop, D.C.; Sparks, P. Predicting household food waste reduction using an extended theory of planned behavior. Resour. Conserv. Recycl. 2015, 101, 194-202. [CrossRef]

21. Karim Ghani, W.A.; Rusli, I.F.; Biak, D.R.; Idris, A. An application of the theory of planned behaviour to study the influencing factors of participation in source separation of food waste. Waste Manag. 2013, 33, 1276-1281. [CrossRef]

22. Mondejar-Jimenez, J.-A.; Ferrari, G.; Secondi, L.; Principato, L. From the table to waste: An exploratory study on behavior towards food waste of Spanish and Italian youths. J. Clean. Prod. 2016, 138, 8-18. [CrossRef]

23. Russell, S.; Young, W.; Unsworth, K.L.; Robinson, C. Bringing habits and emotions into food waste behaviour. Resour. Conserv. Recycl. 2017, 125, 107-114. [CrossRef]

24. Stancu, V.; Haugaard, P.; Lahteenmak, L. Determinants of consumer food waste behavior: Two routes to food waste. Appetite 2016, 96, 7-17. [CrossRef]

25. Stefan, V.; Herpen, E.; Tudoran, A.; Lahteenmaki, L. Avoiding food waste by Romanian consumers: The importance of plan-ning and shopping routines. Food Qual. Prefer. 2013, 28, 375-381. [CrossRef]

26. Visschers, V.H.M.; Wickli, N.; Siegrist, M. Sorting out food waste behaviour: A survey on the motivators and barriers of self-reported amounts of food waste in households. J. Environ. Psychol. 2016, 45, 66-78. [CrossRef]

27. Ajzen, I. From intentions to actions: A theory of planned behavior. In Action Control; Kuhl, J., Beckmann, J., Eds.; Springer: Berlin/Heidelberg, Germany, 1985; pp. 11-39.

28. Ajzen, I. The Theory of Planned Behavior. Organ. Behav. Hum. Decis. Process. 1991, 50, 179-211. [CrossRef]

29. Quested, T.E.; Marsh, E.; Stunell, D.; Parry, A.D. Spaghetti soup: The complex world of food waste behaviors. Resour. Conserv. Recycl. 2013, 79, 43-51. [CrossRef]

30. Secondi, L.; Principato, L.; Laureti, T. Household food waste behavior in EU-27 countries: A multilevel analysis. Food Policy 2015, 56, 25-40. [CrossRef]

31. Setti, M.; Falasconi, L.; Segrè, A.; Cusano, I.; Vittuari, M. Italian consumers' income and food waste behavior. Br. Food J. 2016, 118, 1731-1746. [CrossRef]

32. Graham-Rowe, E.; Jessop, D.C.; Sparks, P. Identifying motivations and barriers to minimising household food waste. Resour. Conserv. Recycl. 2014, 84, 15-23. [CrossRef] 
33. Beck, M.E. Dinner preparation in the modern United States. Br. Food J. 2007, 109, 531-547. [CrossRef]

34. Cox, J.; Giorgi, S.; Sharp, V.; Strange, K.; Wilson, D.; Blakey, N. Household waste prevention-A review of evidence. Waste Manag. Res. 2010, 28, 193-219. [CrossRef]

35. Gofton, L. Dollar rich and time poor? Some problems in interpreting changing food habits. Br. Food J. 1995, 97, 11-16. [CrossRef]

36. Quested, T.E.; Parry, A.D.; Easteal, S.; Swannell, R. Food and drink waste from households in the UK. Nutr. Bull. 2011, 36, 460-467. [CrossRef]

37. Grob, A. A structural model of environmental attitudes and behaviour. J. Environ. Psychol. 1995, 15, 209-220. [CrossRef]

38. Kollmuss, A.; Agyeman, J. Mind the Gap: Why do people act environmentally and what are the barriers to pro-environmental behaviour? Environ. Educ. Res. 2002, 8, 239-260. [CrossRef]

39. Barr, S. Strategies for sustainability: Citizens and responsible environmental behavior. Area 2003, 35, 227-240. [CrossRef]

40. Grandhi, B.; Singh, J.A. What a Waste! A Study of Food Wastage Behavior in Singapore. J. Food Prod. Mark. 2015, 22, 471-485. [CrossRef]

41. Parizeau, K.; von Massow, M.; Martin, R. Household-level dynamics of food waste production and related beliefs, attitudes, and behaviours in Guelph, Ontario. Waste Manag. 2015, 35, 207-217. [CrossRef]

42. Evans, D. Blaming the consumer-Once again: The social and material contexts of everyday food waste practices in some English households. Crit. Public Health 2011, 21, 429-440. [CrossRef]

43. Edjabou, M.E.; Petersen, C.; Scheutz, C.; Astrup, T.F. Food waste from Danish households: Generation and composition. Waste Manag. 2016, 52, 256-268. [CrossRef] [PubMed]

44. Koivupuro, H.-K.; Hartikainen, H.; Silvennoinen, K.; Katajajuuri, J.-M.; Heikintalo, N.; Reinikainen, A.; Jalkanen, L. Influence of socio-demographical, behavioral and attitudinal factors on the amount of avoidable food waste generated in Finnish households. Int. J. Consum. Stud. 2012, 36, 183-191. [CrossRef]

45. Zhang, H.; Duan, H.; Andric, J.M.; Song, M.; Yang, B. Characterization of household food waste and strategies for its reduction: A Shenzhen City case study. Waste Manag. 2018, 78, 426-433. [CrossRef]

46. Quested, T.; Johnson, H. Household food and drink waste in the UK; Wastes \& Resources Action Programme (WRAP): Banbury, UK, 2009; ISBN 1-84405-430-6.

47. Knussen, C.; Yule, F.; MacKenzie, J.; Wells, M. An analysis of intentions to recycle household waste: The roles of past behavior, perceived habit, and perceived lack of facilities. J. Environ. Psychol. 2004, 24, 237-246. [CrossRef]

48. Swami, V.; Chamorro-Premuzic, T.; Snelgar, R.; Furnham, A. Egoistic, altruistic, and biospheric environmental concerns: A path analytic investigation of their determinants. Scand. J. Psychol. 2010, 51, 139-145. [CrossRef]

49. Valle, P.; Menezes, J.; Reis, E.; Rebelo, E. Reverse logistics for recycling: The customer service determinants. Int. J. Bus. Sci. Appl. Manag. 2009, 4, 1-17.

50. Ioannou, T.; Zampetakis, L.A.; Lasaridi, K. Psychological determinants of household recycling intention in the context of the theory of planned behaviour. Fresenius Environ. Bull. 2013, 22, 2035-2041.

51. Zhang, D.; Huang, G.; Yin, X.; Gong, Q. Residents' Waste Separation Behaviors at the Source: Using SEM with the Theory of Planned Behavior in Guangzhou, China. Int. J. Environ. Res. Public Health 2015, 12, 9475-9491. [CrossRef]

52. Von der Embse, N.P. What School Psychologists Need to Know about Structural Equation Modeling; National Association of School Psychologists Communiqué: Bethesda, MD, USA, 2016; Volume 44, pp. 10-12.

53. Hu, L.; Bentler, P.M. Cutoff criteria for fit indexes in covariance structure analysis: Conventional criteria versus new alternatives. Struct. Equ. Model. Multidiscip. J. 1999, 6, 1-55. [CrossRef]

54. Morrison, T.G.; Morrison, M.A.; McCutcheon, J.M. Best Practice Recommendations for Using Structural Equation Modelling in Psychological Research. Psychology 2017, 8, 1326-1341. [CrossRef]

55. Jekria, N.; Daud, S. Environmental concern and recycling behavior. Procedia Econ. Financ. 2016, 35, 667-673. [CrossRef]

56. Ulhasanah, N.; Goto, N. Assessment of citizens' environmental behavior toward municipal solid waste management for a better and appropriate system in Indonesia: A case study of Padang City. J. Mater. Cycles Waste Manag. 2017, 20, 1257-1272. [CrossRef]

57. Arı, E.; Yılmaz, V. A proposed structural model for housewives' recycling behavior: A case study from Turkey. Ecol. Econ. 2016, 129, 132-142. [CrossRef]

58. Jayasinghe-Mudalige, U.; Udugama, J.; Ikram, S. Use of Structural Equation Modeling Techniques to Overcome the Empirical Issues Associated With Quantification of Attitudes and Perceptions. Sri Lankan J. Appl. Stat. 2013, 13, 15. [CrossRef]

59. Khayyam, M.; Chuanmin, S.; Qasim, H.; Ihtisham, M.; Anjum, R.; Jiaxin, L.; Tikhomirova, A.; Khan, N. Food Consumption Behavior of Pakistani Students Living in China: The Role of Food Safety and Health Consciousness in the Wake of Corona-virus Disease 2019 Pandemic. Front. Psychol. 2021, 12, 673771. [CrossRef] [PubMed]

60. Ilakovac, B.; Voca, N.; Pezo, L.; Cerjak, M. Quantification and determination of household food waste and its relation to sociodemographic characteristics in Croatia. Waste Manag. 2020, 102, 231-240. [CrossRef]

61. Barr, S. Factors influencing environmental attitudes and behaviors: A UK case study of household waste manage-ment. Environ. Behav. 2007, 39, 435-473. [CrossRef]

62. Melbye, E.L.; Onozaka, Y.; Hansen, H. Throwing it all away: Exploring affluent Consumers' Attitudes toward wasting edi-ble food. J. Food Prod. Mark. 2016, 23, 416-429. [CrossRef] 
63. Zorpas, A.A.; Voukkali, I.; Loizia, P. A prevention strategy plan concerning the Waste Framework Directive in Cyprus. Fresenius Environ. Bull. 2017, 26, 1310-1317.

64. Zorpas, A.A.; Lasaridi, K.; Voukkali, I.; Loizia, P.; Chroni, C. Promoting Sustainable Waste Prevention Strategy Activities and Planning in Relation to the Waste Framework Directive in Insular Communities. Environ. Process. 2015, 2, 159-173. [CrossRef]

65. Armitage, C.J.; Conner, M. Efficacy of the theory of planned behaviour: A meta-analytic review. Br. J. Soc. Psychol. 2001, 40, 471-499. [CrossRef] [PubMed] 